\title{
Justiça, Identidade e Juventude indígena urbana: um estudo sobre os processos organizativos na Cidade do México
}

Justice, Identity and Urban Indigenous Youth: A Study on Organizational

Processes in Mexico City

Rebecca Lemos Igreja

\section{(2) OpenEdition Journals}

\section{Edição electrónica}

URL: http://journals.openedition.org/aa/4011

DOI: 10.4000/aa.4011

ISSN: 2357-738X

\section{Editora}

Programa de Pós-Graduação em Antropologia Social (UnB)

\section{Edição impressa}

Data de publição: 1 dezembro 2019

Paginação: 129-158

ISSN: 0102-4302

\section{Refêrencia eletrónica}

Rebecca Lemos Igreja, «Justiça, Identidade e Juventude indígena urbana: um estudo sobre os processos organizativos na Cidade do México », Anuário Antropológico [Online], v.44 n.2 | 2019, posto online no dia 03 dezembro 2019, consultado o 27 abril 2021. URL: http://journals.openedition.org/aa/ 4011 ; DOI: https://doi.org/10.4000/aa.4011

\section{@) $\Theta \Theta \Theta$}

Anuário Antropológico is licensed under a Creative Commons Atribuição-Uso Não-Comercial-Proibição de realização de Obras Derivadas 4.0 International. 


\section{Justiça, Identidade e Juventude indígena urbana: um estudo sobre os processos organizativos na Cidade do México}

\section{Justice, Identity and Urban Indigenous Youth: A Study on Organizational Processes in Mexico City}

Rebecca Lemos Igreja Faculdade de Direito, Universidade de Brasília - Brasil

\section{Introdução}

Em meados dos anos 1990, iniciei uma pesquisa sobre o tema "Indígenas urbanos e acesso à justiça na Cidade do México"1 (Igreja, 2004). O início dessa pesquisa se deu em um contexto especial e de grandes mudanças no México, marcado pela reabertura política do país após anos de domínio do Partido Revolucionário Institucional - PRI. Como parte dessa renovação política, observou-se uma abertura para uma discussão mais ampla sobre os direitos indígenas que vão se consolidar em propostas de reformas constitucionais que afirmam e reconhecem o México como um país pluricultural e pluriétnico. Além disso, em termos econômicos, foi instituído o Acordo Norte-Americano de Livre Comércio - NAFTA, levando o país a uma política de descentralização do Estado e de introdução de políticas neoliberais. Como consequência, ao mesmo tempo em que direitos indígenas importantes foram reconhecidos, houve um enfraquecimento das políticas sociais de proteção do Estado importantes para esses povos.

Esses anos também foram caracterizados por processos de resistência, como o levantamento zapatista em 1994, que exigiam uma profunda transformação da estrutura estatal em defesa de uma maior inclusão social, participação política e respeito pela democracia e autonomia dos povos indígenas. Esse momento contribuiu para o que pode ser chamado de ressurgimento do movimento indígena com base na demanda por reconhecimento da autonomia jurídica e política dos povos indígenas. Nesse cenário, a justiça própria indígena, juntamente com a língua, constituiu um elemento básico da identificação étnica desses povos (Stavenhagen, 1990, p. 29).

Grupos indígenas da Cidade do México buscaram integrar-se, igualmente, à luta indígena nacional, criando organizações na cidade. A criação dessas organizações também constituiu um meio fundamental para ter acesso aos benefícios das 
políticas públicas e novas legislações dirigidas a essa população ${ }^{2}$ e tinham, em geral, o formato de uma associação civil. Instituições como o antigo Instituto Nacional Indigenista - INI, e outras mais recentes que foram surgindo na cidade no decorrer de diferentes governos, acenaram com a possibilidade de recursos para projetos produtivos para as organizações formalizadas como associações civis. No entanto, a constituição dessas organizações confrontou-se com uma série de problemas, em grande parte resultantes da dificuldade de reconhecimento da identidade étnica dos indígenas que lhes integravam e que está ligada à forma como a presença indígena na cidade e suas necessidades principais eram consideradas. Também se relacionava a problemas e demandas específicas que envolviam os jovens indígenas que as compunham. Abordar a constituição das organizações indígenas e o processo de reafirmação étnica no contexto da cidade do México colocou em pauta os jovens indígenas e a possibilidade de perpetuação por eles do "ser indígena" ainda estando no contexto urbano.

Novas reformas da Constituição Nacional foram realizadas, destacando a reforma de 2001 que amplia o reconhecimento dos direitos dos povos indígenas. A Constituição mexicana define, em seu artigo $2^{\circ}$, que são considerados como povos indígenas aqueles que descendem de populações que habitavam no território do país quando se iniciou a colonização e que conservam suas instituições sociais, econômicas, culturais e políticas ou parte delas. A consciência de sua identidade indígena é tida como critério fundamental para determinar o acesso aos direitos estabelecidos. Constituiriam as comunidades integrantes de um povo indígena aquelas que formam uma unidade social, econômica e cultural em um território e que reconhecem autoridades próprias, de acordo com seus usos e costumes. Por fim, determina que o reconhecimento dos povos e comunidades indígenas se fará nas constituições e leis das entidades federativas, que deverão levar em conta os princípios gerais e critérios estabelecidos na Constituição Federal.

Uma nova reforma legislativa importante surgiu com a elaboração da nova Constituição da Cidade do México - CDMX em 2018. A cidade deixa de ser um distrito federal, consolidando-se como mais um estado do país, e elabora sua constituição estadual, aprovada em sua totalidade por uma Assembleia Constituinte em 31 de janeiro de 2017. Necessário explicar que o sistema federativo mexicano atribui aos estados a competência para legislar sobre matéria civil com maior autonomia para elaborarem seus próprios códigos civis e legislarem sobre assuntos que não estejam especificados na Constituição Federal ou que sejam por ela autorizados. Por essa 
razão, foi possível que a nova Constituição da Cidade do México contemplasse vários direitos para as comunidades indígenas residentes, especialmente o direito amplo à autonomia jurídica e política, direitos esses não reconhecidos totalmente em vária entidades federativas do país.

A Constituição da Cidade do México - CDMX surge como a mais avançada das constituições estaduais do país e uma das mais avançadas em termos de reconhecimento de direitos indígenas na América Latina, integrando de maneira completa a Declaração das Nações Unidas sobre os direitos dos povos indígenas. Como parte fundamental do reconhecimento dos direitos indígenas, garante o direito à autodeterminação dos povos e comunidades residentes na Cidade do México, nos termos do artigo 59 e dos demais parágrafos. Estabelece, portanto, que a autodeterminação será exercida por meio da autonomia, de acordo com as formas de organização, econômica, política e cultural e sistemas próprios de justiça indígena. No entanto, ela instaura-se em um contexto político regional de questionamento significativo sobre a eficácia dos direitos previstos nas constituições latino-americanas, novas ou reformadas. O que observamos no continente é a falta de efetividade das mudanças constitucionais em relação aos direitos indígenas, muitas vezes resultando em violação dos mesmos.

As dificuldades em garantir esses direitos ampliam-se quando muitas das disposições constitucionais continuam a não refletir a multiplicidade de situações, experiências e formas de organização dos indígenas no contexto urbano, que muitas vezes desafiam a nossa maneira de pensar, definir as identidades étnicas e abordar as necessidades específicas dessa população. Isso diz respeito, especialmente, ao que se relaciona com a resolução de determinados conflitos vivenciados pelos diferentes grupos, especialmente pelos jovens indígenas. Esses jovens são sujeitos centrais na construção do movimento indígena urbano e das organizações e exercem, muitas vezes, papéis aparentemente contraditórios. Por um lado, são os precursores da criação de muitas organizações, especialmente vinculadas à luta pelo comércio ambulante e pelo reconhecimento da diversidade étnica e cultural da cidade. Por outro lado, são também os que trazem maiores questionamentos à construção de uma identidade étnica indígena urbana e são responsáveis, muitas vezes, pelos conflitos que as organizações enfrentam com o sistema de justiça do Estado. Muitos jovens acabam por se envolverem com problemas de criminalidade, delinquência, drogas e trazem para as organizações a fama de serem violentas, desestruturadas e, por fim, "aculturadas". Muitos já não falam a língua materna ou se vestem com os 
trajes tradicionais. O comportamento desses jovens marca negativamente as organizações e lhes dificulta o reconhecimento "étnico" pelas instituições públicas e o acesso aos direitos que lhes são dirigidos.

Assim, portanto, a elaboração de uma nova Constituição na Cidade do México, contemplando essa amplitude de direitos para os indígenas residentes, fortalece a relevância em se analisarem os perfis, as condições sociais, os processos organizativos e a forma de reconhecimento dos indígenas urbanos, especialmente, dos jovens indígenas, como condição necessária para que esses novos direitos não sejam apenas reconhecidos na forma da lei. Neste artigo, busco contribuir com mais esse momento singular de reconhecimento de direitos constitucionais em matéria indígena no México, trazendo um histórico da participação dos jovens nas organizações indígenas da Cidade do México, a partir de quando foram criadas. O foco especial são os conflitos e as relações estabelecidas com o sistema de justiça estatal. Esse histórico traz um testemunho importante do estabelecimento e dos processos organizativos dos grupos indígenas e da adaptação deles aos diferentes contextos políticos da cidade.

\section{Cultura e identidade étnica no contexto urbano}

Embora a presença indígena nas cidades tenda a não despertar o interesse de muitos pesquisadores, há um histórico de estudos sobre o tema importante de ser considerado. Especificamente, os estudos iniciais acabavam por se concentrar sobre o processo de migração, urbanização e posterior assimilação dos povos indígenas, pois, uma vez na cidade, acabariam sendo assimilados pela cultura nacional. Muitos autores seguiram um modelo redfiliano do continuum folk-urbano, que foi projetado para estudar a transformação sociocultural causada pela migração rural em direção às cidades e pela posterior urbanização dos grupos migrantes (Redfield, 1941). Outros estudos foram surgindo contradizendo o modelo de Redfield, tendo como foco, no entanto, uma "cultura da pobreza" que tendia a ser perpetuada devido às condições de subemprego e desemprego, marginalidade e promiscuidade em que os migrantes viviam na cidade (Lewis, 1972).

Anos mais tarde, especialmente a partir da década de 1970, novos estudos buscavam explicar a migração como sintoma de desequilíbrios regionais vinculados com a exploração econômica (Oehmichen Bazán, 2001, p. 7). A deterioração da agricultura de subsistência, o crescimento populacional e o desenvolvimento da indústria permitiriam explicar as causas e os movimentos migratórios (Oliveira; Stern, 1972; 
Muñoz; Oliveira 1974), assim como a presença dos indígenas na cidade do México (Arizpe, 1975, 1978, 1985; Nolasco, 1979; Lomnitz, 1997). Lourdes Arizpe (1975), por exemplo, chamou a atenção dos estudiosos da época para a persistência da diferença étnica e da discriminação frente ao que se esperava, ou seja, a assimilação dos indígenas por uma sociedade urbana regida pelas diferenças de classe. Não obstante, seria a marginalização econômica na cidade que fortaleceria a identidade étnica: "totalmente marginados, sin posibilidad de movilidad social y económica, necesitan del apoyo de su grupo étnico en la ciudad y así, en vez de perderla, reafirman su identidad étnica" (Arizpe, 1975, p. 151).

Um novo enfoque surge a partir da observação de que os migrantes, ao menos da primeira geração, não rompiam com os lugares que deixaram e mantinham vínculos com suas comunidades de origem (Oehmichen Bazán, 2001, p. 8). O envio de dinheiro, a contribuição para a realização de obras e serviços de melhoramento da comunidade, a participação nas festas patronais e o apoio que ofereciam aos novos migrantes na cidade, passaram a constituir um novo enfoque (Orellana, 1973; Romer, 1982; entre outros). Muitas dessas abordagens, no entanto, ao focalizarem os vínculos dos indígenas migrantes com a comunidade de origem, pouco falaram sobre os laços que os indígenas criavam com a própria cidade e sobre os problemas que nela enfrentavam (Igreja, 2004).

Novas pesquisas vão tentar compreender a permanência ou a transformação da cultura indígena no contexto urbano através de conceitos mais abrangentes, como podem ser culturas híbridas (García Canclini, 1989) e criolização (Camus, 2000, p. 39), re-significação (Martínez Casas, 2007) ou transformações culturais (Oehmichen Bazán, 2001), mas denunciam também uma falsa dualidade entre o campo e a cidade, já que os indígenas do mundo rural também estão sujeitos às transformações constantes advindas da modernidade, inclusive através da contribuição dos migrantes. A importância desses enfoques é que abrem a perspectiva da definição do indígena não como reminiscência do passado, mas como uma presença no mundo moderno, com valores culturais e necessidades distintas. Além disso, procuram demonstrar os diferentes rumos em que se pode dar a ressignificação ou transformação cultural, de forma a permitir o reconhecimento de uma verdadeira diversidade cultural.

Pesquisas mais recentes, especialmente realizadas em outras capitais do país, muitas ainda inspiradas nas concepções dos autores mencionados acima, renovam o interesse em analisar as identidades étnicas no contexto urbano (Vásquez Estrada; Prieto Hernandez, 2013)3 ${ }^{3}$, em observar sua inserção no mercado de trabalho 
(Durin, 2013) ${ }^{4}$, em estudar fenômenos como discriminação e racismo (Horbarth,

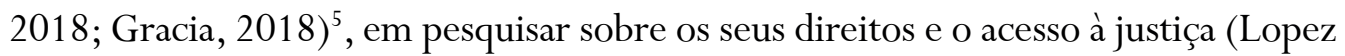
Guerreiro; Garcia Alvarez, 2019) ${ }^{6}$, e de maneira especial, em promover pesquisas sobre juventude indígena.

Maya Lorena, precursora da pesquisa sobre o tema jovens indígenas e indígenas urbanos, explica que, em um primeiro momento, os estudos sobre jovens indígenas tinham seu foco sobre a sua vivência e resistência frente a fenômenos como migração, urbanização e criação de gangues juvenis na cidade (Perez Ruiz, 2008). A autora preocupou-se em desconstruir uma classificação homogênea e universal de ser jovem, para situá-la em contextos específicos, em que as condições sociais e culturais são determinantes. Mais recentemente, novos estudos sobre a juventude indígena centralizam-se no significado de ser jovem e na produção de uma cultura juvenil (Urteaga, 2007), especialmente em um contexto de mobilidades e globalização cultural (Perez Ruiz, 2012, 2014).

Desde os anos 1990, venho me dedicando ao estudo com indígenas urbanos tendo como foco específico a reprodução ou não das tradições jurídicas indígenas na cidade e os conflitos com o sistema de justiça do Estado. Realizei uma pesquisa, em diferentes etapas e com longos períodos de campo etnográfico, que se centrou em uma permanência cotidiana nos locais de moradia, no acompanhamento do trabalho dos representantes indígenas das organizações, em visitas às penitenciárias da cidade onde se encontravam jovens indígenas encarcerados e em visitas e permanência em delegacias e procuradorias que tratavam da matéria indígena. Além disso, foram realizadas diversas entrevistas às autoridades públicas que se responsabilizavam pelas políticas destinadas a eles. Essa pesquisa serviu como base, nos anos 1990, para uma dissertação de mestrado e, em seguida, para a elaboração de uma tese de doutorado no início dos anos 2000. Nos últimos anos, tenho voltado constantemente a campo, procurando acompanhar o desenvolvimento das organizações e a questão indígena nacional.

Como prevê a Constituição Nacional, a existência de autoridades políticas e jurídicas próprias, segundo os usos e costumes, são elementos definidores fundamentais dos povos e comunidades indígenas. No entanto, em um contexto urbano, muitos indígenas encontram-se fragmentados em grupos familiares de tamanho variado, vivendo em moradias multiétnicas, longe da comunidade de origem e de suas autoridades tradicionais e vivenciando experiências sociais e culturais muito diversas, algumas específicas da própria cidade. Nesse contexto, a delimitação ter- 
ritorial e a reprodução das instituições tradicionais, especialmente jurídicas, pelos indígenas se revestem de formas muito variadas e com grande adaptação às condições cotidianas de vida na cidade. Assim, definir-se como pertencente a um povo ou comunidade indígena, especialmente frente às instituições do Estado, revela-se como um desafio; no entanto, é condição necessária para o acesso dos indígenas às políticas públicas e direitos a eles destinados.

A pesquisa levou-me, portanto, a analisar o processo de afirmação e demanda de reconhecimento das identidades étnicas no contexto urbano. Ainda que não tenha sido o enfoque principal, especialmente a discussão sobre a categorização social, o tema dos jovens indígenas se tornou presente e fundamental, já que eles eram considerados pelas instituições como a prova de "aculturação" e "integração" possíveis dos indígenas urbanos. Meu trabalho de campo levou-me a verificar, muitas vezes ao contrário, um contexto de reconstituição de laços comunitários, de reagrupamentos familiares, de recuperação de antigas tradições e da língua nativa e, sobretudo, de luta política pelo reconhecimento de suas identidades étnicas.

Para Barth (1976), a identidade étnica, entendida através de uma noção de contraste que envolve a noção de nós e dos outros, é a marca da diferenciação em confronto com os outros, nas áreas de fronteira que os separam e não especificamente no conteúdo cultural. Dessa forma, a identidade étnica é construída através de um processo de interação em que os grupos se destacam por suas características simbólicas e culturais para manter sua coesão social e se diferenciar. Os grupos étnicos são, portanto, uma organização social cuja característica fundamental está na autofiliação ou na filiação feita por outros a uma categoria étnica, que organiza as interações entre indivíduos e que é a fonte de uma identificação étnica. Barth foi um intelectual pioneiro na relativização da importância dos conteúdos culturais. A partir de sua análise, a identidade passou a ser vista de forma relacional e contextual. Assim, os processos de identidade não existem fora de um contexto específico, pois estão sempre relacionados a algo específico que está em questão e aos interesses do grupo (Agier, 2001). Se seguimos essa visão da identidade como relacional, o contexto urbano é considerado um ambiente propício para o despertar das identidades étnicas.

Os antigos estudos de Mitchell (1956) nos auxiliam, igualmente, a compreender os processos de etnicização no contexto urbano. Suas pesquisas em uma cidade mineira na Rodésia do Norte durante a colonização consideraram que, nas aglomerações urbanas, os contatos entre diferentes tribos se expandiam, constituindo situações em que as pessoas tendiam a categorizar os outros de acordo com algumas 
características visíveis e a ordenar seu comportamento com base nessa categorização que, por sua vez, podia transformar os referenciais originais das comunidades rurais de origem. Na cidade, essas referências seriam selecionadas e reivindicadas quando necessárias em uma determinada situação de contato. Comportamentos que às vezes parecem contraditórios, como em um momento um indivíduo se comportar como parte de uma comunidade e em outro não, na realidade não o são, pois dependem da situação determinada. Assim, portanto, uma noção situacional de identidade é formulada.

A análise das identidades étnicas de forma interativa não apenas se adapta bem ao contexto urbano, mas é útil para compreendê-las em uma situação moderna, na qual contatos entre diferentes culturas são cada vez mais ampliados e há um senso geral de perda de identidade. Se, por um lado, a tendência no mundo moderno parece caminhar para a homogeneização, por outro lado, contatos intensos tendem a privilegiar a formação de identidades ainda mais complexas. Esse modo interacionista de entender as identidades, no entanto, não deve ser visto como uma falta de consideração das bases históricas acumuladas pelos diferentes grupos e do contexto estrutural em que essas relações ocorrem. A cultura tem um importante espaço para formar o repertório de significados e sentidos para os grupos étnicos, mas a relação de identidade e cultura deve ser considerada a partir de contextos específicos e não como uma relação natural e contínua (Agier, 2001).

Por conseguinte, as identidades étnicas assumem contornos complexos no contexto urbano. E nesse contexto surgem grupos étnicos que não necessariamente desencadeiam suas identidades, seu senso de coletividade, em suas relações na cidade, especialmente com as instituições do Estado. Eles constituem grupos étnicos no sentido de um coletivo com uma interação, um reconhecimento mútuo, uma comunicação eficaz, uma comunidade com um senso de solidariedade, uma identidade e um treinamento de ação concertada. Brubaker (2002) explica que a capacidade de ação coletiva pode trazer aquela sensação de "grupeidad", ou seja, pode constituir momentos de coesão profunda e solidariedade coletiva intensa para um objetivo comum a ser atingido, um projeto político comum, social, cultural, mas são momentos contingentes e não fixos.

Esse novo contexto constitucional na Cidade do México, aberto à inclusão dos direitos dos povos indígenas presentes na cidade, leva-nos a refletir uma vez mais sobre o modo como as identidades étnicas e a cultura são consideradas. Os pragmatismos das leis e políticas públicas tendem a não considerar as ambiguidades, a 
multidirecionalidade e a fluidez dos processos identitários, especialmente em contextos urbanos. A consideração da construção desses processos é de fundamental importância, pois são eles que nos aproximam das realidades dessa população e que, portanto, podem contribuir para a efetividade das normas e políticas elaboradas. É a pesquisa empírica e as consultas constantes com essas populações indígenas que podem ajudar na compreensão das formas pelas quais a identidade e a cultura são definidas e vivenciadas na cidade.

\section{A presença indígena na Cidade do México}

A Nova Constituição da CDMX reconhece a composição pluricultural da cidade e, para esse fim, define de maneira particular os povos indígenas sujeitos aos direitos especiais que lhes são proporcionados:

\section{Artículo 58}

Composición pluricultural, plurilingüe y pluriétnica de la Ciudad de México

1.Esta Constitución reconoce que la Ciudad de México tiene una composición pluricultural, plurilingüe y pluriétnica sustentada en sus pueblos y barrios originarios y comunidades indígenas residentes.

2.Se entenderá por pueblos y barrios originarios y comunidades indígenas residentes lo siguiente:

a) Los pueblos y barrios originarios son aquellos que descienden de poblaciones asentadas en el territorio actual de la Ciudad de México desde antes de la colonización y del establecimiento de las fronteras actuales y que conservan sus propias instituciones sociales, económicas, culturales y políticas, sistemas normativos propios, tradición histórica, territorialidad y cosmovisión, o parte de ellas; y

b) Las comunidades indígenas residentes son una unidad social, económica y cultural de personas que forman parte de pueblos indígenas de otras regiones del país, que se han asentado en la Ciudad de México y que en forma comunitaria reproducen total o parcialmente sus instituciones y tradiciones.

3. Se reconoce el derecho a la autoadscripción de los pueblos y barrios originarios y comunidades indígenas residentes y de sus integrantes. La conciencia de su identidad colectiva e individual deberá ser criterio fundamental para determinar a los sujetos que se aplicarán las disposiciones en la materia contenidas en esta Constitución.

Os dados mais recentes indicam que, em 2010, havia 122.411 pessoas de 5 
anos ou mais que falam uma língua indígena na Cidade do México, um número que representa $1,5 \%$ da população total dessa faixa etária. Esse número deve ser tomado sob certas reservas, pois há uma tendência a subestimar a população indígena, devido, entre outros fatores, às condições de localização de numerosos grupos não permitir que eles sejam contados e o fato de que a linguagem é o principal indicador, quando muitos deles já não falam a sua língua.

Os indígenas presentes na Cidade do México não constituem um grupo social homogêneo. Como afirma a Constituição, encontramos na cidade os povos e bairros originários e as comunidades indígenas residentes. Os povos originários Nahua estão localizados no sul da cidade, em Milpa Alta, Xochimilco, Tláhuac, Cuajimalpa, Tlalpan, Magdalena Contreras e Álvaro Obregon, áreas mais rurais. São povoados historicamente dedicados à agricultura. Suas demandas concentram-se, particularmente, na proteção de suas terras que, nos últimos anos, foram divididas e ameaçadas pela crescente urbanização. As comunidades indígenas residentes são constituídas por indígenas de outras regiões do país, inicialmente considerados como migrantes, embora estivessem na segunda ou terceira geração na cidade, ou como residentes, como atualmente são chamados. Suas condições sociais dependem da condição social antes de deixar a comunidade de origem e de como se inseriram no contexto urbano.

A nova Constituição trouxe, também, essa transformação importante na forma de considerar os indígenas já não como migrantes, mas residentes na cidade. A condição de migrantes, no debate da Constituinte, passa a ser vista como uma classificação feita em geral, pelos povos originários (que se diferenciam dos indígenas migrantes apresentando-se como "originários") que teria matizes discriminatórios, segundo propostas interpretativas dos próprios grupos (Lucas Campo, 2016). No entanto, podemos considerar que a condição de residentes cria novas fronteiras com novos indígenas migrantes, que continuamente chegam à cidade e que se veem isolados desse debate.

A Constituição reconhece o direito à autoidentificação das comunidades indígenas residentes e seus membros. Para isso, considera que o critério fundamental é a consciência coletiva e individual dos sujeitos. Essa autoidentificação, no entanto, não tem sido suficiente para garantir esse reconhecimento perante as instituições e, como mencionado anteriormente, uma das razões está relacionada à maneira como as identidades étnicas são pensadas e definidas, além da evidente discriminação de que os indígenas urbanos são vítimas. 
Encontramos na cidade, profissionais, intelectuais e trabalhadores indígenas em diferentes condições sociais. Encontramos grupos organizados, grupos familiares extensos, famílias isoladas, indígenas que reivindicam uma filiação étnica e outros que buscam se integrar à cidade. Muitos dos grupos indígenas que estão mais em contato com instituições estatais, especialmente aqueles em condições sociais mais desfavoráveis, formaram as organizações étnicas, geralmente no formato de associações civis. Os grupos Otomí, Mazahua e Triqui, que foram classificados pelas instituições, especialmente pelo antigo Instituto Nacional Indígena (INI), como de extrema pobreza e com os quais realizei a pesquisa, encontram-se na cidade em condições precárias de vida. Muitos deles realizam suas atividades no setor informal, como comerciantes ambulantes, habitam em edifícios em más condições e se confrontam diariamente com a justiça do Estado na condição de vítimas e réus de crimes. Os Otomí contactados eram, em grande parte, originários de Santiago Mezquititlán, no sul do estado de Querétaro. Grupos Mazahua são originários do Estado do México e, por sua vez, os Triqui de Oaxaca. É importante trazer a história da constituição desses grupos para compreender as dificuldades para se adaptarem ao contexto atual.

As organizações indígenas, especialmente Mazahua, Triqui e Otomí constituíram-se como associações civis nos anos 1990, com o objetivo principal de ter acesso à promoção dos Fundos Regionais que eram parte do Programa Nacional de Solidariedad, um programa social de assistência pública, que, no caso dos indígenas, era gerido pelo Instituto Nacional Indigenista. Surgiram com propostas de projetos produtivos, especialmente, para o apoio à venda ambulante de artesanatos. O INI, além de apoiar na elaboração desses projetos, oferecia aos grupos cursos de capacitação de líderes, de prevenção de delitos, de atenção infantil e oficinas produtivas. Mais tarde, com a entrada de outros governos na cidade e a criação de novas instituições, novos cursos foram surgindo, como o de defensor jurídico.

As associações surgiram de grupos indígenas, em geral familiares, que juntos ocupavam espaços de moradia na cidade. Nesse momento de sua criação, os próprios indígenas referiam-se a si mesmos e/ou eram vistos especialmente pelas instituições, como pertencentes a grupos indígenas migrantes e não a comunidades. Grupos, por se constituírem com base nas relações familiares, em pequeno número ou em aglomerações de famílias, todas vivendo em um mesmo espaço, ou com base no compartilhamento de um mesmo espaço de venda de comércio ambulante. Também havia organizações constituídas por companheiros e companheiras 
de uma mesma cidade de origem, mas que viviam dispersos pela cidade, em diversos bairros. As organizações e os grupos indígenas possuem constituição bastante diversa na cidade.

O comércio ambulante é um importante aglutinador dos grupos indígenas. Em geral, na chegada à cidade, os homens empregavam-se na construção civil e as mulheres trabalhavam como empregadas domésticas. No entanto, foram se inserindo no comércio ambulante, atividade exercida na maior parte do tempo sem autorização formal ${ }^{7}$. Algumas organizações foram formadas com o objetivo de obter um espaço de venda, principalmente no Centro Histórico. As mulheres Mazahua, principalmente de San Antonio Pueblo Nuevo, povoado do Estado do México, destacaram-se desde a sua chegada à cidade, pela venda de frutas e sementes nas ruas. Além disso, vendiam alimentos, brinquedos, CDs piratas e bonecas tradicionais, entre outras coisas. Triqui e Otomi vendem, em geral, artesanato, especialmente as bonecas típicas. O comércio de rua parece ser o emprego ideal, pois oferece melhores recursos do que empregos de baixa qualificação profissional, além de permitir que principalmente as mulheres, devido ao horário mais flexível, estejam com seus filhos regularmente e mais próximas de seu grupo, parentes, vizinhos da mesma comunidade de origem. A atividade no comércio ambulante é considerada por muitos indígenas, principalmente pelas vendedoras Mazahua, como parte de suas próprias culturas.

Muitos grupos indígenas vivem em terrenos baldios, onde constroem casas com papelão e chapas de alumínio, sem infraestrutura. Nesses terrenos podemos encontrar 30, 40 ou mais de 100 famílias do mesmo grupo étnico vivendo juntas. Outros vivem em prédios deteriorados, especialmente no centro histórico da cidade. Muitos desses espaços foram conseguidos através de ocupações irregulares e se encontram constantemente em disputa judicial.

Nos últimos anos, alguns grupos Mazahua e Otomí conseguiram novas habitações de programas de moradia popular nas periferias da cidade, mas muitos habitavam no centro da cidade, em geral, em "vecindades" (cortiços) constituídas em prédios históricos em condições muito deterioradas, colocando suas vidas em alto risco.

En la vecindad (Belisario Domínguez) había gente urbana, y había Mazahua, la gente urbana siempre nos criticaba, que éramos cochinos, que éramos muy cerrados y raro era la persona de los Mazahuas que teníamos luz, y entonces la necesidad era tanta que pura vela se usaba en el cuartito que tenía mi mamá. Casi la 
mayoría de los paisanos usaban velas. Esa vecindad era de gente urbana, pero poco a poco, cada quien se desocupaba, yo creo que por lo mismo de la gente que buscaban los judiciales iban desalojando, entonces entre vecinos, que se desocupaba alguien y quien podía pagar era quien se quedaba con la vivienda, entonces poco a poco se fue invadiendo de paisanos, y allí puros paisanos llegaron casi la mayoría (representante Mazahua - entrevistada durante trabalho de campo).

As diversas organizações Mazahua eram denominadas com o nome da rua onde se encontrava a vecindad em que viviam. Sua presença na cidade não é recente. Já os estudos de Lourdes Arizpe (1975), nos anos 1970, mencionavam a presença das "Marias", como eram denominadas as mulheres Mazahua e Otomi, que vendiam em vias públicas. As famílias de San Antonio Pueblo Nuevo e Providencia (Estado do México) viviam perto do Mercado de Artesanato La Merced e nas ruas do Centro histórico de Belisario Domínguez, Guatemala, Cuba, Moneda, San Marcos e Santísima. Com o tempo, a inserção dos Mazahua na cidade foi se transformando. Se Lourdes Arizpe observava um isolamento desses grupos em suas tradições, vemos agora que eles se envolveram intensamente com o contexto urbano. Meus primeiros contatos me levaram várias vezes a perguntar onde estava a identidade desses grupos, principalmente das últimas gerações. Eles, em geral, não utilizam mais seus trajes, muitos já não falam sua língua nativa e não se imaginam voltando para suas comunidades de origem, por falta de mercado de trabalho. Na cidade, consideram que podem contar com serviços de saúde, acesso a melhores produtos de consumo, alimentos e tecnologia. Assim, eles se consideram moradores da cidade, ainda enfrentando os problemas típicos dela, como a delinquência e a dependência de drogas entre os jovens. No entanto, permanece um senso de coletividade, como continuar a reproduzir as formas tradicionais de convivência, as redes de alianças familiares e de grupo, como fazem sempre referência a suas cidades de origem, e a elas regressam para as festas e para enterrar seus mortos. Enquanto isso, na cidade eles têm suas vidas entrelaçadas, vivem próximos um dos outros; compartilham festas, batismos, casamentos; e se apoiam no confronto com os "outros", as gangues de rua e as autoridades.

O comércio ambulante ainda é a grande atividade dos grupos Mazahua, além de outras atividades marginais, como limpar o para-brisa dos carros nos semáforos. Mas a cidade foi transformando e, embora os problemas com a polícia continuem, o comércio ambulante cresceu e gerou outras oportunidades para esses grupos. A forma de inserção deles ser vista como um longo processo. Desde que chegaram à cidade, os grupos Mazahua foram pressionados a renunciar à sua cultura de origem 
diante do que consideram como atitudes discriminatórias e rejeição, como xingamentos públicos, ameaças cotidianas de expulsão da cidade e, de maneira especial para as mulheres Mazahua, o corte de suas tranças por transeuntes e policiais de ronda como uma forma de agressão à sua condição indígena, situações essas já relatadas nos antigos trabalhos de Lourdes Arizpe ${ }^{8}$. Assim, muitos deles reconhecem que não ensinaram suas línguas a seus filhos e deixaram alguns de seus costumes, como o uso de roupas típicas, alimentando assim uma maior rejeição dos jovens pela sua cultura. Esses mesmos jovens foram integrados na sociedade e "modernizaram" suas roupas, suas atitudes, seus modos de vida.

No, no les enseñé Mazahua porque..., porque la verdad, a mí me daba pena de enseñarle a mis hijos Mazahua, porque..., lo que luego a veces me decía mi papá. Sí porque sí decía mi papá: "A tus hijos, hija, ya no les vas a enseñar Mazahua. Que les enseñe que hablen español, porque va a llegar un tiempo que ya no va a hablar Mazahua y todos van a hablar español, y que s' hijo van a entender eso de castellano. Mejor háblale castellano, lo poquito que usted sepa, háblale el castellano. Y entonces..., de..., ahí sí, siempre le hablaba y luego a mí, a veces, me..., bueno, me daba coraje si querían hablar Mazahua. Le digo: "no, no hable Mazahua, porque después no van a saber ni hablar como yo, que no sé ni hablar.” Les decía.Y ahora, no. Y ahora como..., como yo ya valoro lo que es mi cultura y como soy y siento que, así como somos valemos mucho más que un mestizo. ¿Por qué? Porque de lo que nosotros tenemos, un mestizo no lo tiene. Porque yo luego me pongo a pensar. Un mestizo tendrá estudio, tendrá todo lo que quiera, tendrá dinero de todo el mundo, pero no tiene lo que tiene un indígena. Un indígena no abandona sus costumbres. Un indígena no abandona sus culturas. Un indígena siempre recuerda sus cosas (entrevista de campo, representante Mazahua).

As mudanças constitucionais e as novas políticas voltadas para os indígenas trouxeram mudanças importantes. Hoje, representantes alegam que ganham identidade e já se distanciam da imagem dos "marginais" da cidade. "Cuando llegamos sí había mucha discriminación porque indio era para ellos significado ya de marginales, pero ahora con tantas bandas, con tantos delincuentes y violencia en la ciudad ya no somos los peores, ya no somos la amenaza” (otomí, organização Cuba 53, rua em que se encontra a vecindad).

Em um momento de ressurgimento étnico, ser índio significa prover uma cultura e, por meio dela, diferenciar-se desse mundo delinquente que se encontra na cidade. Mesmo em atividades periféricas, como a venda de chicletes nas ruas, a lavagem de 
para-brisas nos semáforos e o comércio ambulante, os indígenas defendem que eles fornecem uma referência cultural que os distingue.

Jovens indígenas das gerações posteriores, testemunhos das discriminações sofridas por seus pais e por eles mesmos, foram se adaptando à cidade e assumindo a cultura citadina como suas. Principalmente no início da pesquisa, nos anos 1990 e princípios dos anos 2000, eram muitos os jovens que não se afirmavam publicamente como indígenas, declarando sempre que seus pais eram e não eles. Mudaram suas formas de falar, de vestir, pintaram seus cabelos, adquiriram modismos próprios da cidade. No entanto, a difícil inserção em diferentes âmbitos, a vivência dos conflitos diários normais da cidade e a violência não lhes deixavam outra opção a não ser seguir vinculados a suas redes familiares e comunais, necessárias para sua sobrevivência. Esse difícil processo pode auxiliar na explicação da introdução dos jovens indígenas na delinquência e nas drogas.

A vida em vecindades, em condições precárias, especialmente no centro histórico, contribuía para os diversos conflitos que enfrentavam as famílias com seus filhos. Não era raro encontrar no meio dela jovens se drogando e homens alcoolizados. Além disso, eram recorrentes casos de maltrato de crianças e de violência familiar:

¿Qué será vivir en una vecindad? Yo le veo así, aunque un niño no fuera hacer nada malo, pero si está viendo que los otros se están activando, o están viendo que están haciendo unas tonterías allí, quiera o no quiera, los niños se acercan de ellos y creen que los mismos son buenos. Y entonces mejor solos. Si un niño quiere de plano hacer esas cosas a lo mejor se está por cierto para allí, pero no en una vecindad. Entonces yo digo que en una vecindad aprenden muchísimas cosas. Hay muchos problemas de violación y de problemas también entre los vecinos que luego se están agarrando, luego se están peleando (entrevista de campo, representante Mazahua).

Da mesma forma, grupos Otomí, especialmente originadas de Santiago de Mexquititlán, com exceção de algumas organizações que obtiveram novas vivendas, encontram-se em condições precárias de moradia. No entanto, em um ritmo diferente, também produziram mudanças em suas condições de vida nos últimos anos. Os Otomi também vivem em condições de extrema pobreza, geralmente em grandes áreas onde constroem casas feitas de chapas de alumínio sem qualquer infraestrutura. Eles se concentram na venda de artesanato e muitas mulheres com seus filhos, como nos anos 1970, continuam dedicando-se à mendicância. Embora 
tenha melhorado, o nível de escolaridade ainda é muito baixo. Os problemas desses grupos com a justiça são grandes, principalmente pelas crianças que frequentemente são vítimas de maus-tratos ou abandono. Em geral, suas organizações são mais fechadas, conservam muitas de suas tradições e mantem um trânsito mais intenso entre a cidade e a comunidade de origem. Muitos indígenas continuam a falar sua língua e muitas senhoras continuam a usar suas roupas tradicionais. A conformação das organizações Otomí não foi realizada pacificamente. Em alguns casos, houve conflitos entre eles, como ocorreu entre a organização Otomí Zona Rosa A. C. (conhecida como Chapultepec 342), o Grupo Otomí de Chapultepec 380 e a Associação de Artesãos Otomí. A disputa pela habitação desempenha um papel importante nesses conflitos.

Allá en el pueblo, mucha gente no tiene que comer. El alimento del diario es la tortilla con sal, con salsa si se cuenta con algunos centavos. Es con lo que uno alcanza a sobrevivir. Son pocos los que tienen algún ganadito, pollo o un cerdito, un borrego. Eso nos obligó, nos animó a salirnos de nuestro pueblo y venir a la ciudad a buscar alternativas, porque aspiramos a cosas mejores para nuestros hijos.

Yo me vine con la ilusión de seguir estudiando, porque allá terminé la secundaria, como otros más de mis hermanos que querían venir, trabajar y seguir estudiando. Llegamos aquí y nos encontramos que la realidad de la ciudad es otra, no es lo que nosotros creíamos. Y bueno, aun así, no nos doblamos.

A finales de 1994 llegó mi madre a mi casa y me dijo, hay un predio que lo están ocupando, hay un espacio, podemos estar. No hay luz, no hay agua, no hay drenaje, pero podemos entrar, hay que buscarle todo. Bueno, yo le dije, pues vamos a ver. Vi que había pura gente que yo conocía y que incluso muchos son familiares. Pues vine, platiqué con ellos y me decían, hay este espacio, ¿lo quieres ocupar? Pues ahí está (representante otomi).

A constituição das organizações também esteve motivada por conflitos existentes entre os vizinhos e, especialmente, os jovens.

Mira, hay momentos que uno tiene que ser enérgico, otro va a hablar bien, otro con cariño, otro va a perder la paciencia. Bueno, nosotros cuando hay que ser enérgicos, cuando se trata de que un problema, la organización tiene la capacidad de hacerlo. Es la máxima autoridad la asamblea, nosotros, bueno cuando yo llegué al predio, nosotros seguíamos con el problema de la drogadicción, de alcoholismo, existía alcoholismo, la gente dormía tomada, levantaba tomada, todo el día, enton- 
ces, este, empezamos a organizarnos y llegó un momento que dijimos que vamos a constituir una asociación civil. La gente dijo: ¿quién va a encabezar a la organización? La gente dijo: estás tú, señalaron otros compañeros, secretarios, y otros. Entonces la gente dijo: quédate tú como coordinador de la organización. Digo: va a ser una bronca muy dura, hay muchas broncas, si ustedes quieran que yo esté al frente van a aceptar mis condiciones, y ya les dije cuáles son mis condiciones. Mi primera condición es que tenemos que participar. Tenemos que trabajar juntos, si queremos lograr algo, tenemos que trabajar, unos con trabajo, otros con participación y comisiones, la mayoría trabajando, forzosamente en una organización, todos entran o mientras hay apoyo de algunos compas con estos se trabaja. Entonces, órale, entramos, ¿cuál es la otra condición? La otra condición: arreglamos un reglamento interno aquí adentro y lo tenemos que respetar. ¿Cuál es tu otra condición? La otra condición es que mandamos a todos los niños a la escuela. Órale, mandamos a todos los niños. ¿Cuál es tu otra condición? La otra condición es que mantengamos limpio el espacio que estamos ocupando y a los niños lo más que podamos.Y así yo trabajo. (representante Otomí relatando a constituição de sua organização).

As organizações indígenas se viram pressionadas pelas instituições para solucionar os sérios problemas que enfrentam. Ainda com alguma dificuldade e de forma bastante intermitente, algumas delas contaram com o apoio de assistentes sociais oferecido pelas instituições públicas capitalinas. Os representantes creem que devem buscar mecanismos para o que o grupo esteja mais unido e organizado, criando condições para que possam aceder aos recursos para os projetos produtivos. Com esse fim, representantes Mazahua e otomi buscaram revitalizar algumas tradições normativas das comunidades de origem como forma de solucionar querelas e violência entre seus integrantes. Na verdade, tais grupos buscaram convocar assembleias, nas quais conversam com as partes e buscam realizar uma mediação.

Pues estamos tratando de combinar las dos cosas, no podemos llevar todo como estamos acostumbrados, aquí es diferente; pero tratamos de relacionar las dos, sabemos que aquí la justicia, o la impartición de justicia, son distintas, los problemas son distintos, entonces no es forzoso, los problemas no tienen la misma salida, entonces se tienen que combinar las dos cosas. Algo que hacemos nosotros con los problemas que tenemos en los grupos, es primero conocemos la cosa, tratamos no de enfrentar a las personas involucradas, sino que platicar en separado. Primero platica con uno, bueno, tú estás de acuerdo en resolver el problema, que, si ya está de acuerdo que se termina el problema, entonces ya no enfrenta las dos personas, sino que las familias ya vienen con esa certeza de arreglar las cosas y resolver el problema (representante Otomí). 
É importante ressaltar que as assembleias realizadas nos grupos tratam de vários tipos de problemas: brigas entre vizinhos, mau comportamento, agressões, falta de pagamentos de cotas comunitárias, entre outros. Evitam tratar de temas complexos e graves como violências contra as crianças e conflitos conjugais. Em geral, em casos mais graves recorrem ao sistema de justiça do Estado.

Ainda que em algumas organizações, muitos avanços tenham sido observados em termos de diminuição da violência, essa tem sido uma tarefa difícil. Muitos dos integrantes não reconhecem os representantes como autoridades. Em geral, são jovens e/ ou mulheres que constituíram as organizações e não são vistos como autoridades tradicionais. Além disso, é notório que os mais jovens se sentem mais livres na cidade para contradizer o que lhes definem como "normas tradicionais". Sem falar que o recurso à justiça do Estado sempre está disponível e não são poucas as vezes que a ela recorrem quando se sentem prejudicados nas decisões tomadas nas assembleias. Devem ser acrescentadas como dificuldade as divisões existentes em muitas organizações, criadas através de disputas de poder pelo seu controle e por recurso, assim como por questões de divisão religiosa interna ${ }^{9}$.

\section{Os conflitos com a administração de justiça na Cidade do México}

Sem dúvida, é a participação no comércio ambulante, com frequência exercida sem autorização oficial, que gera mais conflitos com os órgãos de justiça do Estado. São mulheres, jovens e crianças que andam vendendo nas ruas e são sujeitas a todo tipo de violência, não somente de outros habitantes da cidade, mas dos policiais que circulam pelas ruas. De maneira especial, um cenário de maior violência ocorre nos momentos de desocupação das ruas pela polícia. Muitos indígenas são presos e não é raro que sejam acusados de agressão e de abuso de autoridades.

Tengo la experiencia con mis hijos, hizo un año y medio en marzo, apenas empezaba los granaderos el levantamiento, bueno, ya había hecho el primero, era el segundo creo. Entonces mis hijas estaban vendiendo quesadillas y yo quise defenderlas con mis manos, y tenía la chiquita con un año y me llevan a las dos hijas, mi hija tenía 21 y la otra 19, se las llevaron y luego llevaron dos de mis sobrinas, pues luego a otra muchacha (indígena Mazahua).

A relação dos indígenas com a polícia é sempre muito conflitiva. Na cotidianidade das ameaças e das buscas policiais, os indígenas são comumente vítimas de abusos. Levam jovens, a quem acusam de roubo e de tráfico de drogas, muitas vezes 
sem prova, gerando indignação de suas famílias que usualmente não sabem e não tem como se defender, sobretudo quando não falam espanhol.

As vecindades são, igualmente, frequentemente invadidas por delinquentes que cometem roubos e agressões, mas os policiais também invadem o espaço para extorquir os indígenas, como pude observar em diversas situações de trabalho de campo. Nesse cenário, os indígenas sentem pouca confiança para poder pedir auxílio em situações graves de violência que enfrentam. São relatados casos de assassinatos de jovens, de agressões e estupros às mulheres das vecindades, muitos cometidos por não indígenas. Em muitos desses casos, não foi possível obter o apoio devido da justiça na busca dos culpados. Comumente, as autoridades lhes recomendam a voltarem para suas comunidades de origem porque, em suas palavras, a cidade não é lugar para eles .

Nos casos acompanhados na pesquisa, em que os indígenas eram culpados dos delitos, as instituições de justiça atuavam de maneira preconceituosa, estereotipando-os, catalogando-os como delinquentes sem lhes oferecer seus direitos de defesa. Em um dos casos mais interessantes, uma jovem Otomí foi retirada de sua família sob a acusação de maltrato. Sua filha, de 11 anos, acusou a mãe de obrigá-la a trabalhar nas ruas da cidade, de não lhe pagar parte da venda e de não lhe permitir ir à escola. A jovem menina era viciada em drogas e conforme conta, foi iniciada por um comerciante que vendia perto de sua mãe. Além disso, estava envolvida com um grupo de jovens mais velhos e, de acordo com sua mãe, já estava se prostituindo. A mãe alegou que o trabalho da sua filha era necessário para o sustento da família e que, ela mesma, teve de trabalhar desde criança em sua comunidade. A jovem foi retirada de sua mãe pela justiça, assim como seus irmãos, e entregue a outra pessoa da família. Independentemente das acusações feitas, o processo não foi aberto para o diálogo e não havia um tradutor. É fato que a mãe falava espanhol, mas também se pode afirmar que não houve nenhuma abertura para a presença de um tradutor de línguas indígenas ou para o apoio de uma instituição pública que se ocupa deles. Nesse caso específico, a família vivia ao redor da cidade e não estava vinculada diretamente a uma organização. O responsável, em uma entrevista que pude realizar sobre o caso, manifestou:

No están tan integradas, más bien pensando por ellas mismas y por su familia y no por un grupo. Yo creo que están moviéndose por intereses particulares, yo creo eso. Eso sucede porque se desintegra, sucede porque alguien tiene más noción 
de progresar que otros, no van a estar apoyando siempre a este grupo y llegan a cambiar, o va a ser una persona distinta al grupo e integra a una familia nueva, con costumbres nuevas, que no depende de la influencia del grupo.

A identidade desempenha um papel fundamental nesses confrontos, uma vez que também é colocada em discussão pelos promotores e juízes, que influenciam diretamente na decisão dos indígenas em negarem ou afirmarem suas identidades. Essa postura é frequente. Em um caso específico, que venho analisando em detalhe em vários textos (Igreja, 2004), na primeira audiência realizada, o juiz negou a participação da representante indígena como testemunha, alegando: "ustedes no tienen por qué estar aquí, ellos no son indígenas, revisamos y todos nacieron aquí, por lo tanto, no son indígenas”. Sobre o fato, a representante comentou:

Mis hijos aquí nacieron y no quiere decir que porque aquí nacieron dejan de ser Mazahua, yo lo puedo comprobar, yo he registrado aquí y he registrado allá, pero esto no quiere decir que les van a hacer de menos que otros, posiblemente, a lo mejor no pueden hablar bien la lengua [indígena] pero entienden unas cosas. No es apenas el idioma, sino que la cultura de dónde venimos, no más aquí. Vuelvo a repetir, es querer imponer sus leyes, también cosas que yo le decía que es siempre, siempre nos han tenido. Por eso es que lo digo, desgraciadamente desconocemos muchas cosas, por eso yo en la verdad me da mucha tristeza en ver un caso como esto y luego pensando de donde vinimos, porque creo que no se vale que las autoridades nos hacen menos que uno, porque ellos tienen más conocimiento, más preparación, ellos saben porque están dentro de la ley y la ley es la ley, cierto, estamos de acuerdo que posiblemente sí, sí tienen sus reglamentos, pero tampoco no tiene por qué hacer esto, no pueden privar un derecho.

Durante a pesquisa de campo, vários casos recolhidos atestavam tal situação de não reconhecimento da identificação étnica do jovem indígena:

Hace poco que un muchacho lo detuvieron también por vía pública. ... Ese muchacho tenía un mechoncito aquí blanco y con un pantalón de mezclilla de, este, cholos, con una playerota, y con esos Nikes, grandotes, así está vestido el muchacho, que es de mi organización.... y la hora que había llegado el muchacho no habían dejado entrar ni su mamá, ni su tía, ni nadie; yo entré y le digo: mira, yo ya llamé por teléfono la delegación, la delegación le llamó por teléfono a ustedes y no encontraban aquí ninguno indígena. Pero, me dijeron que aquí estaba el muchacho indígena y, este, no... y agarra la juez y dice: No, aquí no hay ninguno muchacho indígena, el muchacho que ustedes dicen que se hace pasar por indígena habla 
perfectamente español, así que no se traba nada ni nada. Le digo: mira señora, su madre es una indígena, el muchacho tal vez no se quiera reconocer como indígena, pero la mamá es indígena y si estoy aquí es por la mamá que no sabe expresar y no sabe decir nada y por eso estamos aquí con ella, y ya le dije, y la mamá que nunca sabe hablar bien el español y ni supo hablar muy bien el Mazahua, le digo.Y agarra a la señora y dijo: "es que usted callase, que si va a hablar a su hijo habla en español y no le hable a su lengua”. Le digo, le digo: “me va disculpar usted, señora Juez, ella tiene todo el derecho de hablar como ella si le da la gana, ella tiene una lengua y yo desde al principio dije que es una indígena, ella no habla castellano y habla su lengua y su hijo lo entiende para que usted no diga que no es hijo de una indígena, el muchacho entiende ahorita lo que habla su mamá y no tiene ninguno derecho usted de privar sus derechos de la señora”. Yo le dije y la señora dijo: “usted tiene la razón” (representante Mazahua).

Apesar dessas situações de falta de reconhecimento e discriminação no sistema de justiça, a constituição das organizações e a presença dos representantes indígenas trouxeram, pouco a pouco, importantes oportunidades de defesa dos indígenas, uma vez que foram abertas as portas para a reivindicação de outros direitos. Como resultado concreto desse processo, foi criada uma agência do Ministério Público para cuidar somente de casos que os envolvessem.

Além disso, muitos jovens Mazahua participaram em cursos de capacitação, quiseram recuperar as suas tradições, especialmente a sua língua. Muitos deles continuam a conviver com seus pais reproduzindo e reforçando esse sentimento de coletividade, de identificação étnica. Eles são educados por seus pais, estão com eles, visitam suas comunidades de origem, participam de tradições, festivais e, mais importante, vivem um sentimento de pertencimento étnico e cultural. Os jovens tiveram a oportunidade, como agentes externos e ao mesmo tempo internos, de descobrir o melhor de sua cultura e o que consideravam inadequado reproduzir. As organizações foram bastante importantes para repensar suas próprias culturas. Para entendê-los, é necessário compreender a cultura não através de sua objetivação, incorporada em tradições tangíveis, a-históricas, mas de uma compreensão da identidade étnica como dinâmica e reconstruída cotidianamente. Nesse sentindo, é necessário recuperar a noção de identidades étnicas que mencionamos, conforme Barth. 


\section{O momento atual}

A nova Constituição pode contribuir ainda mais para o reconhecimento dos direitos indígenas, pois abre uma série de garantias em termos de acesso à justiça. De fato, outras mudanças importantes já vinham acontecendo nos últimos anos, como a maior presença de tradutores indígenas nas agências do Ministério Público que recebem as queixas e estabelecem os inquéritos. Ao mesmo tempo, isso não tem sido suficiente para enfrentar problemas comuns que ainda persistem e novos que surgiram e se agravaram nos últimos anos.

Em recente entrevista de campo, em 2018, a um advogado indígena, funcionário de uma agência do Ministério Público responsável por casos envolvendo indígenas, ele relatou que ainda persistem graves problemas no acesso à justiça dos jovens indígenas. Segundo ele, delitos envolvendo jovens indígenas aumentaram na mesma proporção que a delinquência e violência da cidade. Muitos desses casos envolvem não necessariamente os grupos étnicos mais conhecidos e mais em contato com as instituições, mas outras etnias que se encontram na cidade e que não viveram o mesmo processo organizativo. A diferença, segundo ele, é que, nesse momento, os delitos em que estão envolvidos esses jovens são agravados pelo contexto específico de violência no país, marcado pela intensificação do narcotráfico e pelos conflitos entre gangues da cidade. Jovens indígenas e não indígenas encontram-se lado a lado nesse cenário.

Não há novos estudos mais aprofundados sobre os casos de violência atual em que estão envolvidos os jovens indígenas. Desde o início de minha pesquisa com eles, verifiquei que essa violência cotidiana a que estão expostos repercute de maneira geral no grupo do qual fazem parte. Organizações Mazahua e Otomí pesquisadas, que tiveram acesso a programas de habitação, a melhores condições de trabalho e que sofriam com problemas graves de criminalidade, avançaram muito no controle da situação. Outras organizações continuam lutando com velhos problemas que levam não só a que os jovens delínquam, mas que eles mesmos sejam vítimas da arbitrariedade da polícia ou da violência da própria cidade. Além disso, famílias indígenas Mazateca, Tzotzil, entre outras etnias, como relata o advogado, dispersas pelos mercados de artesanato próximos do centro da cidade vivem processos importantes de fragmentação e de violência. Apesar dos novos direitos reconhecidos, não se observam políticas de prevenção de delito e nem os cursos sobre violência e direitos humanos nas organizações que costumavam ser realizados no passado.

Mas o novo contexto constitucional traz, especialmente, novos desafios. Como 
prevê a nova Constituição, as comunidades indígenas residentes têm garantida a sua autonomia política e jurídica. Para isso, devem organizar melhor seu corpo de autoridades e selecionar os delitos dos quais vão se ocupar da solução, sempre dentro dos limites estabelecidos pela norma estatal. O relato que trago sobre o passado dos grupos indígenas que chegaram à cidade, a constituição de suas organizações e os problemas para o reconhecimento de suas identidades étnicas, especialmente em se tratando dos jovens indígenas, já demonstram a dificuldade de aplicação e de efetividade dessa autonomia na cidade.

No final de 2018, retornei aos representantes indígenas para lhes perguntar sobre a nova Constituição. Eles expressam uma preocupação com o novo formato organizativo que se lhes pedem para o reconhecimento desse direito: comunidades com autoridades estabelecidas. Como relato no princípio deste texto, grupos familiares indígenas constituíram na cidade organizações, como associações civis, conforme era demandado naquele momento, para ter acesso a recursos para projetos produtivos, venda ambulante, habitação etc. Essas associações são muito diversas e de tamanho bem variável. Além disso, muitas foram constituídas com propósitos definidos, como a venda ambulante e a luta pela moradia, a partir de parentes dispersos pela cidade. Representantes das associações não são vistos, em muitas situações, como autoridades tradicionais; e as assembleias de mediação de conflitos são, em geral, bastante informais. Além disso, novas habitações multiétnicas foram concedidas aos indígenas de várias regiões e etnias. O que vemos nessas habitações são regulamentos de boa convivência que são estabelecidos. Há de se fazer a ressalva que depende também do grupo étnico, da experiência particular de inserção na cidade e da herança ou não de uma justiça indígena existente na comunidade e que busca se adaptar à cidade. Não trato neste artigo de outros exemplos, em que organizações de outras etnias buscaram estabelecer um sistema de regulação interna bastante mais sólido, ainda que enfrentando muitos problemas. São casos mais pontuais que analiso em outras oportunidades.

A Constituição não prevê uma obrigatoriedade para o reconhecimento dos indígenas que se apresentem como "comunidades", mas tampouco prevê outros espaços de participação, especialmente política, a partir de suas especificidades e demandas. Não há previsão para representações políticas individuais como indígenas, como poderiam ser as cotas representativas. Há vários "lutadores indígenas", como se apresentam alguns representantes, que mesmo não liderando organizações importantes e numerosas, participam ativamente da luta pelos direitos indígenas. 
Essa situação torna-se mais complexa frente à necessidade da Agência do Ministério Público que se ocupa da assistência aos indígenas em demandar uma delimitação dos delitos que podem ser resolvidos pela justiça própria da comunidade indígena urbana. O desafio, segundo os responsáveis da agência, é estabelecer o declínio de competência desses delitos para a comunidade. Necessário, portanto, que as organizações indígenas mudem seu status de associação civil, estabeleçam-se como comunidades e organizem a sua jurisdição indígena na cidade.

Apesar de a autodeterminação ser uma demanda dos povos indígenas, representantes indígenas da cidade preocupam-se com mais esse movimento, que segundo eles, ainda chega de maneira vertical, e que lhes impõe um novo desafio de se adaptar às expectativas institucionais sobre o "indígena". Além disso, refletem o que essa mudança trará em termos de melhorias para suas condições de vida na cidade e na luta contra a discriminação da qual são vítimas.

\section{Considerações finais}

A pesquisa com os indígenas urbanos traz elementos importantes para repensar as identidades étnicas, especialmente em grandes cidades modernas. Chama a atenção a dificuldade de aceitação dos indígenas nesse contexto, que são considerados como os "fora de lugar". Há um esquecimento da história da presença indígena nas cidades pré-coloniais latino-americanas, como é o caso da própria cidade do México. No entanto, as marcas dessa antiga presença estão por todos os lados, nos sítios arqueológicos, nos nomes das ruas e avenidas, na arquitetura da cidade. $\mathrm{Na}$ busca por reconhecimento de seu direito de estarem na cidade, os indígenas vivem situações ambíguas, nas quais se apresentam como cidadãos mexicanos como todos os demais, com demandas de saúde, moradia, educação; e como uma população diversa culturalmente, com referentes tradicionais, com estruturas sociais diferenciadas, com vínculos profundos com as comunidades de origem, sendo eles mesmos pertencentes a povos indígenas que se encontram em todas as regiões do país. $\mathrm{O}$ reconhecimento dos indígenas na cidade implica em uma dissociação da ideia "indígena = camponês”, necessária para a luta contra a discriminação que sofrem. As novas gerações estão estabelecidas na cidade de forma permanente e não buscam o retorno a suas comunidades.

Os jovens indígenas são atores importantes na construção do movimento indígena na cidade. Muitos participaram do processo organizativo, vincularam-se à luta pelos direitos indígenas. Circulam entre diferentes cenários políticos da cidade, 
frequentam diferentes âmbitos sociais e questionam constantemente a realidade em que vivem. Como todo e qualquer jovem da cidade, vivenciam a modernidade, anseiam por novas tecnologias e se confrontam com o mundo conflitivo a que estão expostos. Como jovens indígenas, vivem as imposições de suas heranças culturais, questionando-as constantemente, ao mesmo tempo que, imersos na cotidianidade em sua cultura de origem, buscam valorizá-la e aproveitar o espaço político que o reconhecimento como indígena lhes proporciona.

A nova Constituição abre possibilidades e direitos fundamentais para o reconhecimento da cultura indígena na cidade. Possibilita, além disso, um fortalecimento da luta antidiscriminatória e antirracista. O grande desafio, no entanto, está em reconhecer a diversidade da manifestação cultural e identitária, que não pode ser limitada por uma compreensão homogênea do ser indígena na atualidade.

Recebido: 30/04/2019

Aprovado: 30/08/2019

Rebecca Lemos Igreja é Antropóloga Jurídica, professora do Departamento de Estudos Latino-Americanos - ELA e do PPG da Faculdade de Direito da Universidade de Brasília. Membro do Conselho Superior Internacional da Faculdade Latino-Americana de Ciências Sociais - FLACSO. Pesquisadora fundadora do Colégio Latino-Americano de Estudos Mundiais (Programa FLACSO/Brasil). Coordenadora do Laboratório de Estudos Interdisciplinares sobre Acesso à Justiça e Direitos nas Américas - LEIJUS/UnB e do Grupo de Estudos Comparados México, Caribe, América Central e Brasil - MeCACB (CNPq/Brasil). ORCID: 0000-0002-95332985. Contato: rebeccaigreja@unb.br

\section{Notas}

1. Esta pesquisa iniciou-se em 1996, foi também parte de um projeto, financiado pelo Conacyt, coordenado pela Dra. Maria Teresa Sierra do CIESAS/México, que propôs apresentar um estudo nacional sobre justiça indígena e sua relação com a lei estatal, entre os anos de 1998 e 2001. Meu trabalho de campo estendeu até 2005 e foi atualizado nos anos seguintes. Sobre o projeto especi- 
ficamente, ver Igreja (2004).

2. Consideramos neste texto população indígena urbana como sendo conformada por representantes, grupos e famílias indígenas pertencentes a povos indígenas de várias partes do país que migraram à Cidade do México, denominação de acordo com as instituições públicas e estudos sobre a configuração populacional da cidade.

3. Vásquez Estrada e Prieto Hernandez realizam pesquisa importante sobre a presença indígena na cidade de Querétaro, trazendo amplas informações sobre o perfil sociodemográfico e a cotidianidade dessa população.

4. Séverine Durin vem desenvolvendo, desde o início do século XXI, importantes pesquisas sobre os indígenas urbanos na cidade de Monterrey. Seu foco especial tem sido no trabalho doméstico realizado pelas mulheres indígenas e o processo de subordinação e discriminação a que estão sujeitas.

5. Jorge Horbath, em suas pesquisas nas cidades caribenhas do sudeste mexicano, e Amália Gracia, em Guadalajara, colocam o foco na vivência dos indígenas na cidade e os processos de discriminação e racismo dos quais são vítimas.

6. Jahel López Guerrero e Luis Fernando García Álvarez trabalham sobre o reconhecimento de direitos dos indígenas urbanos, especialmente jovens.

7. Entre os Otomi, havia uma grande porcentagem, especialmente de mulheres, que estavam nas ruas pedindo esmolas, e era comum encontrar Mazahua nos sinais de trânsito vendendo bebidas e chicletes ou limpando para-brisas.

8. Os antigos estudos de Lourdes Arizpe e as narrativas dos representantes indígenas por mim recolhidas durante o trabalho de campo demonstram que o processo de adaptação à cidade foi marcado pela discriminação, pela segregação e pela vida difícil em bairros em condições precárias. Durante a pesquisa, pude reconstruir histórias de vida dos representantes das organizações que demonstram o difícil processo de adaptação à cidade e a luta pelo reconhecimento como cidadãos, como os mesmos direitos de ir e vir na cidade (Igreja, 2000).

9. Relato com mais detalhes o funcionamento das assembleias e os casos que aí são tratados na minha dissertação de mestrado , tese de doutorado e em artigos escritos posteriormente.

\section{Referências}

AGIER, Michel. 2001. "Distúrbios identitários em tempos de globalização”. Mana, São Paulo, n. 7, p. 7-33.

ARIZPE, Lourdes. 1975. Indígenas en la ciudad de México: el caso de las Marías. México: Secretaria de Educación Pública.

ARIZPE, Lourdes. 1978. Migración, etnicismo y cambio económico: un estudio sobre indígenas en la ciudad de México, México: El Colegio de México.

ARIZPE, Lourdes. 1985. Campesinato e migração. México: Secretaria de Educación Pública.

BARTH, Fredrik. 1976. Los grupos étnicos y sus fronteras. México: Fondo de Cultura Económica.

BRUBAKER, Rogers. 2002. "Ethnicity without groups”. University of California. Select Works, Disponível em: http://works.bepress.com/wrb/7. Acesso em: 
CAMUS, Manuela. 2000. Ser indígena en ciudad de Guatemala. Tese (Doctorado en Ciencias Sociales) - Universidad de Guadalajara y el CIESAS, México.

DURIN, Séverine. 2013. "Servicio doméstico de planta y discriminación en el área metropolitana de Monterrey”. Relaciones - Estudios de historia y sociedad, v. 34, n. 134, p. 93-129.

GARCÍA CANCLINI, Néstor. 1990. Culturas híbridas: estrategias para entrar y salir da modernidad. Ciudad do México: Grijalbo.

GRACIA, Maria Amália. 2018. "Vivir y ser indígena en la Zona Metropolitana de Guadalajara, México”. En: GRACIA, Maria Amália; HORBATH, Jorge E. (Eds.). La cuestión indígena en las ciudades de las Américas: procesos, políticas e identidades. Buenos Aires: Consejo Latinoamericano de Ciencias Sociales (CLACSO). p. 293-310.

HORBATH, Jorge. 2018. "Indígenas em tres ciudades caribeñas del sureste mexicano: percepciones de la discriminación y tensiones en su identidad”. En: GRACIA, Maria Amália; HORBATH, Jorge E. (Eds.). La cuestión indígena en las ciudades de las Américas: procesos, políticas e identidades. Buenos Aires: Consejo Latinoamericano de Ciencias Sociales (CLACSO). p. 169-188.

IGREJA, Rebecca Lemos. 2000. Derecho y diferencia étnica: la impartición de justicia hacia los indígenas migrantes en la ciudad de México. Disertación (Master en Anthropologie Sociale) - Centro de Investigaciones y Estudios en Antropología Social, CIESAS, México.

IGREJA, Rebecca Lemos. "Negociando identidades. La participación de los jóvenes en las organizaciones indígenas de la ciudad de México”. En: PEREZ RUIZ, Maya Lorena. Jóvenes indígenas y globalización en América Latina. México: Instituto Nacional de Antropología e Historia (INAH). p. $219-238$.

IGREJA, Rebecca Lemos. "Derecho y diferencia étnica: la impartición de justicia hacia los indígenas migrantes en la ciudad de México”. In: SIERRA, María Teresa (Ed.). Haciendo justicia: interlegalidad, derecho y género en regiones indígenas. México: Ciesas/Miguel Ángel Porrúa. p. 409-474. LEWIS, Oscar. 1972. La cultura de la pobreza. Barcelona: Cuadernos Anagrama.

LOMNITZ, Larissa. 1997. Cómo sobreviven los marginados. México: Siglo XX.

LOPEZ GUERREIRO, Jahel López; GARCIA ALVAREZ, Luis Fernando. 2019. "Juventudes indígenas urbana, derechos y ciudadanías contemporáneas en América Latina”. ABYA-YALA - Revista sobre acesso à justiça e direitos nas Américas, Brasília, v. 3, n. 1.

LUCAS CAMPO, Laurentino. 2016. “IIndígenas migrantes o residentes en la Ciudad de México?”. Sinfín Revista Electrónica, n. 20, p. 53-63. Disponible en: http: / /www.revistasinfin.com/wp-content/uploads/2016/11/Sinf\%C3\%ADn-20.pdf . Acceso en: 18 jun. 2019.

MARTÍNEZ CASAS, Regina. 2007. Vivir invisibles. La resignificación cultural entre los Otomíes urbanos de Guadalajara. México: CIESAS.

MITCHELL, James Clyde. 1956. The Kalela Dance: aspects of social relationships among urban Africans in Northern Rhodesia. Manchester: Manchester University Press.

MUÑOZ, Humberto; OLIVEIRA, Orlandina de. 1974. "Migración y desigualdad social en la ciudad de México”. In: MUÑOZ, Humberto; OLIVEIRA, Orlandina de; SINGER, Paul; STERN, Claudio (Comps.). Las migraciones internas en América Latina: consideraciones teóricas. México: El Colegio de México. 
NOLASCO, Margarita. 1979. Cuatro ciudades: el proceso de urbanización dependiente. México: INAH.

OEHMICHEN Bazán, Cristina. 2001. Mujeres indígenas migrantes en el proceso de cambio cultural: análisis de las normas de control social y relaciones de género en la comunidad extraterritorial. Tese (Doctorado en Antropología) - Facultad de Filosófica y Letras, UNAM, México.

OLIVEIRA, Orlandina. 1997. "Migración femenina, organización familiar y mercados laborales en México”. Comercio Exterior, México, v. 34, n. 7.

ORELLANA, Carlos. 1973. "Mixtec migrants in Mexico City: a case study of urbanizations?" Human Organisations, v. 32, n. 3, p. 273-285.

PEREZ RUIZ, Maya Lorena. 2008. "Diversidad, identidad y globalización: los jóvenes indígenas en las ciudades de México”. En: PEREZ RUIZ, Maya Lorena. Jóvenes indígenas y globalización en América Latina. México: Instituto Nacional de Antropología e Historia (INAH). p. 45-67.

PEREZ RUIZ, Maya Lorena. 2012. “Desnaturalizar la noción de “jóvenes indígenas”. En: GÜEMES PINEDA, Miguel; QUIRÓZ CARRANZA, Roxana (Eds.). Jóvenes y globalización en elYucatán de hoy. Mérida: Ediciones de la Universidad Autónoma de Yucatán. p. 17-44.

PEREZ RUIZ, Maya Lorena; VALLADARES DE LA CRUZ, Laura. 2014. Juventudes indígenas: de hip hop y protesta social en América Latina. México: INAH.

ROMER, Martha. 1982. Comunidad, migración y desarrollo: el caso de los mixes de Totonpec. México: INI.

STAVENHAGEN, Rodolfo. 1990. "Derecho consuetudinario indígena en América Latina”. En: STAVENHAGEN, Rodolfo; ITURRALDE, Diego (Comps.). Entre la ley y la costumbre. México: Instituto Indigenista Interamericano. p. 27-46.

URTEAGA CASTRO-POZO, Maritza. 2007. La construcción juvenil de la realidad: jóvenes mexicanos contemporáneos. Tese - (Doctorado en Ciências Antropológicas). Universidad Autónoma Metropolitana, México.

VÁZQUEZ ESTRADA, Alejandro; PRIETO HERNÁNDEZ, Diego. (2013). Indios en la ciudad: identidad, vida cotidiana e inclusión de la población indígena en la metrópoli queretana. Querétaro: CONACULTA, INAH, Gobierno del Estado de Querétaro, CONACYT. 
Resumo: Especialmente a partir dos anos 1990, grupos indígenas da Cidade do México criaram organizações como um meio importante para ter acesso às políticas públicas e às novas legislações em matéria indígena. A constituição dessas organizações, no entanto, confrontou-se com uma série de problemas, em grande parte resultantes da dificuldade do reconhecimento da identidade étnica desses grupos, devido à forma como a presença indígena na cidade e suas necessidades principais são consideradas. Esse reconhecimento é ainda mais questionado quando se trata dos jovens indígenas que estão na cidade. Um novo momento surge com a elaboração da nova Constituição da Cidade do México em 2018, que contempla vários direitos para as comunidades indígenas residentes, especialmente, o direito à autonomia jurídica e política. É sob a perspectiva da participação dos jovens nas organizações indígenas, especialmente com relação aos conflitos com a justiça do Estado, que apresento a reflexão sobre "ser indígena" no contexto urbano.

Palavras-chaves: indígenas urbanos; jovens indígenas; cidade do México; identidade étnica; justiça indígena
Abstract: Especially since the 1990s, indigenous groups in Mexico City have created organizations to access public policies and new legislation in indigenous matters. The constitution of these organizations, however, has faced several problems, largely as a result of the difficulty of recognizing the ethnic identity of these groups, due to the way in which the indigenous presence in the city and its main needs are considered. This recognition is even more questioned when it comes to the indigenous youths who are in the city. A new moment arises with the elaboration of the new Constitution of Mexico City in 2018 that contemplates several rights for resident indigenous communities, especially the right to legal and political autonomy. It is from the perspective of the participation of young people in indigenous organizations, especially in relation to conflicts with the justice, that I present the reflection on "being indigenous" in the urban context.

Keywords: urban indigenous; youth indigenous; Mexico City; ethnic identity; indigenous justice 